\title{
Modelling a temperature regime of a railway track structure and its comparison with the results of experimental measurements
}

\author{
S. Hodas \& L. Ižvolt \\ Department of Railway Engineering and Track Management, \\ Faculty of Civil Engineering, University of Žilina, Slovak Republic
}

\begin{abstract}
Following the completed experimental monitoring of the temperature regime of the construction of a subgrade structure on the experimental stand of the Departments Railway Engineering and Track Management and measurement of thermal conductivity coefficients $\lambda$ of building materials used in construction of a subgrade structure, there are constructed mathematical models, which are designed to not only verify the temperatures obtained in individual structural components of subgrade structure of experimental stand, but also the possibility to use appropriate software to model temperature regime of other types of constructions of subgrade structures. The paper presents mathematical models for the typical winter periods, which have been recorded since the beginning of the experimental measurements conducted from 2003 to the end of the winter period of 2013 using the software SV-HEAT SVOFFICE SoilVision [1] and there are also comparisons presented in achieving the position of zero isotherm in the construction of a subgrade structure. At the end of this paper, some of the knowledge obtained from the mathematical modelling of the temperature regime of the construction of a subgrade structure and confrontations with the temperature regime of a monitored, real railway track are underlined.

Keywords: railway, temperature regime, zero isotherm, modelling.
\end{abstract}

\section{Introduction}

All constructions of linear traffic buildings are exposed to traffic and non-traffic load during their operating life, which actually means that they are exposed to 
static or most dynamic load and climatic factors, particularly the effect of water and frost. Due to the requirement of a design of operationally safe and long-term reliable track, it is necessary to qualify and quantify the size of the traffic and non-traffic load and then, where the railway track, design not only suitable construction of track removal, as well as the appropriate type of subgrade construction, its proper material composition and dimensions of structural layers.

Qualification and quantification of traffic and non-traffic load operation on the construction of the railway track, its structural layout and dimensions can be performed using experimental measurements on the running tracks for real operating load and real effect of climatic factors during the year. Above all, quantification and qualification of the climatic factors in real time is a very timeand labour-consuming, because individual seasons are different during particular years not only in terms of temperature (maximum and minimum air temperatures obtained, length of time of exposure and the amount of change in the temperature of air), but also in terms of the occurrence and intensity of rainfall, or monitoring of non-traffic load during winter is important, whether it is a precipitation of rain or snow (snow unlike water has thermo-insulation characteristics). Since the monitoring of real impact of traffic and non-traffic load on dimension design of subgrade construction and quality of the track during its operation is time- and financial-consuming, the appropriate software products are increasingly being used to simulate traffic and non-traffic load. Following the results of long-term monitoring of the temperature regime of subgrade structure on the experimental model of the Department of Railway Engineering and Track Management - DRETM (see the following paper [2] at this conference) and the need to amend the basic legislative document for the design of the construction of subgrade structure [3], there have been established laboratory coefficients of thermal conductivity of building materials built in the experimental model of the DRETM located in the original premises of the Faculty of Civil Engineering (Experimental Stand DRETM I) and subsequently processed designs of models of railway track constructions.

The purpose of the process of scientific research is the comparison of the results obtained during the temperature regime and freezing depth of the construction of subgrade structure in real winter conditions of experimental model and verification of the values of thermal conductivity coefficients $\lambda$ observed at the same time in materials incorporated in the construction of the experimental model (details of determining coefficients of thermal conductivity $\lambda$, including measurement methodology and description of the measurement equipment described in [4]). At the same time there was performed comparison of setting of the software model and actual course of the temperature regime of the experimental measurements carried out on Experimental Stand DRETM I, determination of the required input values for the relevant simulation of temperature regime of subgrade structure and freezing depth reached and also due to their use of the newly built model of railway track (Experimental Stand DRETM II), where experimental measurements started from the winter 2013/14. 


\section{Characteristic of the Experimental Stand DRETM I}

The modelling of the temperature regime of a railway track, which is characterized in Chapter 3, is implemented on the Experimental Stand DRETM I in fig. 1, where a long-term monitoring of temperature regime and freezing depth of subgrade structure of railway track model in 1:1 has been in progress since 2003/04.
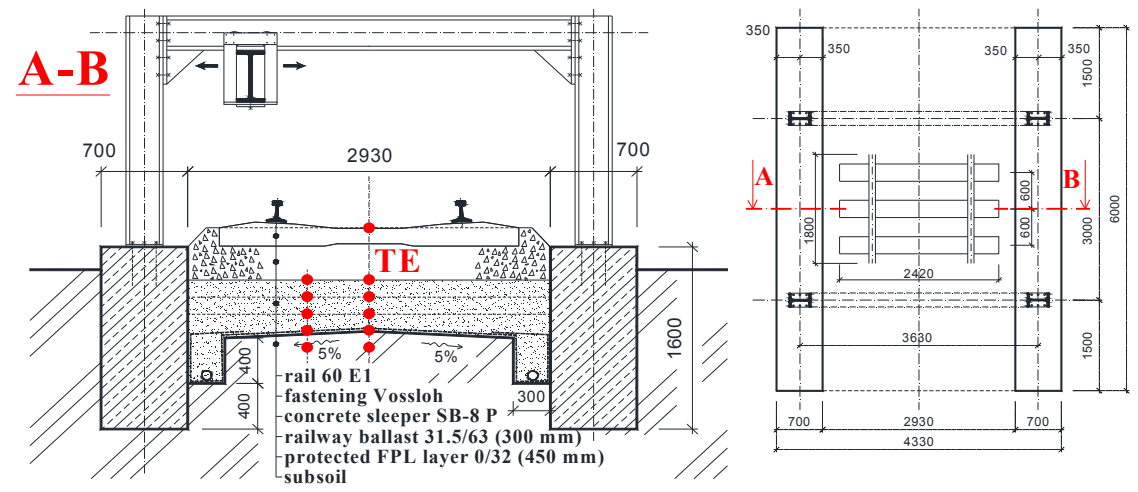

Figure 1: Experimental Stand DRETM I.

The construction of the railway track in the Experimental Stand DRETM I, which can be characterized as a railway track conducted at ground level, consists of the following structural layers (in fig. 1):

- base of ballast - thickness of $500 \mathrm{~mm}$ - fraction of $31.5 / 63 \mathrm{~mm}$,

- subbase of crushed aggregate - fraction 0/32 mm - thickness of $450 \mathrm{~mm}$,

- reinforced geotextile MACRIT GTV 50/50 B placed on the subgrade surface,

- $\quad$ subgrade surface of sandy clay $(\mathrm{F} 4=\mathrm{CS})$ established in the double-sided cross gradient of $5 \%$.

There are 11 resistance thermometers in total (their location is shown in fig. 1) built in along the height of structural layers of the experimental model of the railway track, which continuously monitor the temperature in the environment.

\section{A short description of the mathematical model of the Experimental Stand DRETM I}

The modelling of temperature regime of the construction of the Experimental Stand DRETM I and properties of incorporated materials of its individual structural layers are simulated and mathematically modelled using Canadian software SV-HEAT SVOFFICE SoilVision [1]. As it was highlighted in the previous section of the text, the main purpose of the mathematical modelling is to simulate temperature regime of real construction of railway track model (Experimental Stand DRETM I) and subsequent confrontation in the courses of 
freezing construction of subgrade structure and the position of zero isotherm obtained. In order to meet the assignment of this task there were selected following representative winter periods:

- winter period with the highest freezing index achieved (winter 2005/06),

- winter period with the lowest freezing index achieved, and concurrently the lowest depth of frost of the construction (winter 2006/07),

- winter period with the greatest depth of frost of the construction achieved (winter 2011/12).

Under the mathematical modelling using the software SV-HEAT [1], there is enabled accurate dimensional assignment of individual structural components of Experimental Stand DRETM I and assignment of specific physico-mechanical properties of structural materials inbuilt, which were laboratory found for all the structural layers (identified as areas $R i$ in the mathematical model) in fig. 2.

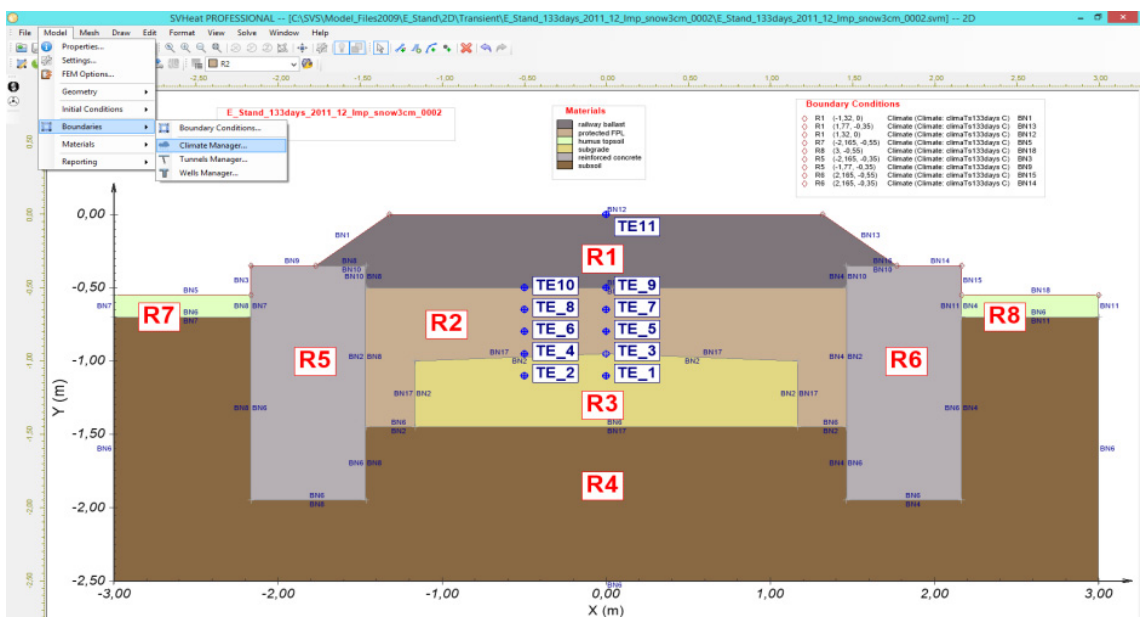

Figure 2: Mathematical model of Experimental Stand DRETM I.

Important characteristics also include the way of temperature transitions within the temperature regime of individual structural layers (structural areas) and also the position of the borders between these structural areas. Experimental Stand DRETM I with its structural layout and composition is specific to the transitional areas, for example, a typical construction of railway superstructure and fixed railway track, or tunnel, bridge and etc.

There are required settings of laboratory values of materials inbuilt in individual structural areas of mathematical model identified as $R_{i}$ (in total shown in Table 1):

1. Thermal conductivity expressed as coefficient $\lambda$ in $J /($ day.m.C) for frozen and unfrozen material (methods: constant value, tabular data, equation, DeVries, Johansen, Johansen-Lu et al., etc.),

2. Volumetric heat capacity (soil dry density $\rho$ expressed in $\mathrm{kg} / \mathrm{m}^{3}$, specific 
heat capacity of solid component $c$ expressed in $\mathrm{J} /(\mathrm{kg} . \mathrm{C})$,

3. Soil freezing characteristic curve (SFCC) - temperatures of freezing and thawing of the material of structural layer $T_{e f}$ and $T_{e p}$ expressed in ${ }^{\circ} \mathrm{C}$,

4. Volumetric water content (VWC) - material humidity $w$ (as saturated water content SatVWC and VWC in \%).

Table 1: $\quad$ Selected characteristics of structural areas Ri for the mathematical model of the Experimental Stand DRETM I.

\begin{tabular}{|c|c|c|c|c|c|c|c|}
\hline \multirow{2}{*}{$\boldsymbol{R}_{\boldsymbol{i}}$} & \multirow{2}{*}{ Material } & $\boldsymbol{\lambda}$ & $\boldsymbol{\rho}$ & $\boldsymbol{c}$ & $\boldsymbol{T}_{\boldsymbol{e f}}$ & $\boldsymbol{T}_{\boldsymbol{e}}$ & $\boldsymbol{w}$ \\
\cline { 3 - 8 } & & $\mathrm{J} /($ day.m.C) & $\mathrm{kg} / \mathrm{m}^{3}$ & $\mathrm{~J} /(\mathrm{kg} . \mathrm{C})$ & ${ }^{\circ} \mathrm{C}$ & ${ }^{\circ} \mathrm{C}$ & $\%$ \\
\hline $\mathbf{R 1}$ & railway ballast & 53654 & 1908 & 980 & -0.01 & -0.5 & 1.3 \\
\hline $\mathbf{R 2}$ & protected FPL & 92448 & 1956 & 1233 & -0.01 & -0.5 & 3.8 \\
\hline $\mathbf{R 3}$ & subgrade & 129945 & 2081 & 1585 & -0.01 & -0.5 & 17.5 \\
\hline $\mathbf{R 4}$ & subsoil & 104630 & 1770 & 1582 & -0.05 & -1.5 & 15.7 \\
\hline $\mathbf{R 5}, \mathbf{R 6}$ & reinforced concrete & 123552 & 2300 & 1020 & -0.01 & -0.5 & 20.0 \\
\hline $\mathbf{R}$, R8 & humus topsoil & 120960 & 1800 & 1000 & -0.01 & -0.5 & 20.0 \\
\hline
\end{tabular}

\section{Mathematical modelling of temperature conditions}

The most important settings of the mathematical model include external climatic conditions and internal temperature regime of individual structural layers of the railway track model. External climatic conditions represent daily average mean air temperature measured $2 \mathrm{~m}$ above the ground $T_{M \text {,air }}$ or on the surface of the model construction $T_{M \text {,surface }}$ in the winter period. In our case, the mathematical modelling applied to the temperature of the surface of the track ballast, which was continuously measured by a digital thermometer and recorded on the recording device in increments of 30 minutes and directly from the place of the experimental model.

Climate conditions also include the value of the amount of snow cover in the winter, while it changes during the winter period (boundaries of model $B N_{i}$, where $i=\mathrm{R} 1(1,13,12), \mathrm{R} 7(5), \mathrm{R} 8(18), \mathrm{R} 5(3,9), \mathrm{R} 6(15,14)$ in fig. 2). For example, the course of daily mean temperatures at the surface of the model $T_{M \text {,surface }}$ in the point TE_11 in winter 2011/12 is presented in fig. 3 where $T_{M \text {,surface }}=\left(T_{7}+T_{14}+2 . T_{21}\right) / 4$ is the temperature measurements on the surface of track ballast in times: 7:00 (7 am), 14:00 (2 pm) and 21:00 (9 pm).

In our case, there was intended with snow cover of height of $0.10 \mathrm{~m}$ for days of its occurrence recorded for winter 2005/06. Snow cover was manually maintained to the required thickness, a real fact of track was simulated, where trains run on and they "adjust" its height while driving in relation to the profile of the vehicle. Experimental model was maintained without snow cover in winter 2006/07 and 2011/12 (or with a maximum value up to $0.03 \mathrm{~m}$ ) with an emphasis to cause the most adverse effect of temperature during freezing days. 
Initial setting of temperature of the individual structural areas (layers) $R_{i}$ inside the construction of railway track model is complicated and very important characteristic. It means what heat was accumulated in the construction observed before the actual freezing process. These values were obtained in the mathematical model and for its evaluation using the software $S V$-HEAT from experimental measurements of all built-in thermometer TE_1 to TE_10 and there was considered the day before $1^{\text {st }}$ day when own measurements of the temperature regime of the relevant winter period were instituted.

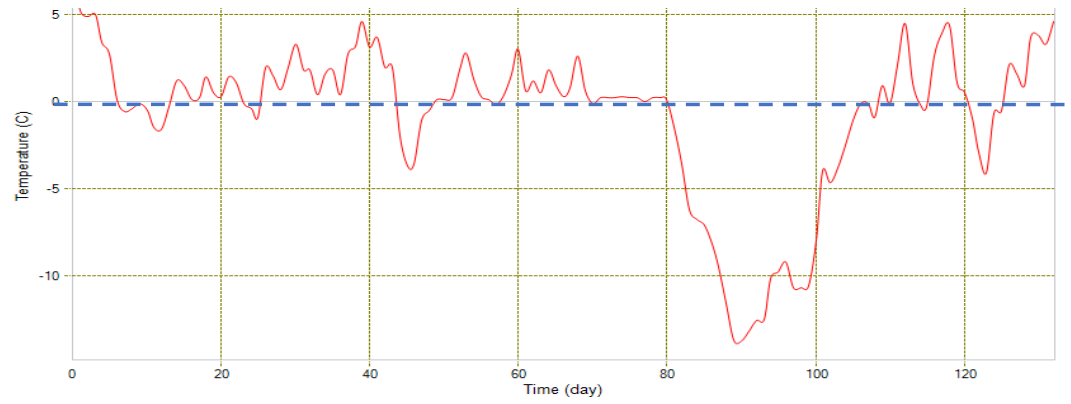

Figure 3: Daily mean temperature on the surface $T_{M \text {,surface }}-\mathrm{TE}_{-} 11133$ days (period from 5.11.2011 to 16.3.2012).

All climatic characteristics that were considered for the mathematical modelling of the temperature regime of experimental model using the software $S V$-HEAT are shown in Table 2.

Table 2: Climatic characteristics of each winter periods.

\begin{tabular}{|c|c|c|c|c|c|c|c|}
\hline & $T_{M, \text { air }}$ & $T_{M, \text { air }}$ & $I_{F, \text { air }}$ & $I_{F, \text { sur }}$ & $\boldsymbol{h}_{F}$ & \multirow{2}{*}{$\begin{array}{c}\text { Characteristics } \\
\text { of the winter period }\end{array}$} & Snow \\
\hline Winter & $\max { }^{\circ} \mathrm{C}$ & $\min { }^{\circ} \mathrm{C}$ & ${ }^{\circ} \mathrm{C}$ & ${ }^{\circ} \mathrm{C}$ & $\mathrm{m}$ & & $\mathrm{m}$ \\
\hline 2005/06 & 5.7 & -16.7 & $\underline{388}$ & $\underline{248}$ & 0.82 & $\begin{array}{l}\text { the highest freezing index } \\
\left(\boldsymbol{I}_{F}^{\max }, \boldsymbol{I}_{\boldsymbol{F} \text {, surface }}\right)\end{array}$ & 0.10 \\
\hline $2006 / 07$ & 13.0 & -5.3 & $\underline{16}$ & $\underline{14}$ & $\underline{0.33}$ & $\begin{array}{l}\text { the lowest freezing index }\left(\boldsymbol{I}_{F \text {,surface }}{ }^{\min }\right) \\
\text { and the smallest freezing depth }\left(\boldsymbol{h}_{F \min }\right)\end{array}$ & 0.00 \\
\hline $2011 / 12$ & 4.9 & -15.2 & 238 & 207 & $\underline{0.98}$ & the largest freezing depth $\left(\boldsymbol{h}_{F}{ }^{\max }\right)$ & 0.03 \\
\hline
\end{tabular}

\section{Analysis of the results of mathematical modelling of the temperature regime of the construction of railway track model}

The great advantage of mathematical modelling is the fact that the results of the temperature regime obtained using the software $S V$-HEAT can be compared with the results achieved on a real model of railway track in all its structural layers (in our case, with the construction of the Experimental Stand DRETM I) and then after their comparisons, these principles can also be used for other constructions of subgrade structure, or different climatic course of winter period without the 
need of their real building and subsequent long-term monitoring. In order to compare the mathematical modelling of the temperature regime of the construction railway track model and the values obtained by experimental measuring on the real construction of the railway track, there were thermometers placed in different structural layers and their interfaces (fig. 1). This subsequently allowed to perform the verification of the correctness of setting of relevant physico-mechanical parameters of the materials inbuilt in the test construction and to assess the optimality of the method using simulation software $S V$-HEAT on a mathematical model shown in fig. 2. This procedure can be regarded as a calibration of the inputs used and the values of variables in the environment $S V$-HEAT, where the resulting values are compared with the actual measured values of temperature in the body of track model (Experimental Stand DRETM I). The courses of temperatures of the constructions of railway track model compared are shown in detail in Table 3 and it is possible to observe a very good consistency in the results.

Table 3: The comparison of temperatures of mathematical modelling in $S V$-HEAT and experimental measurements - point TE_3 (railway subgrade).

\begin{tabular}{|c|c|c|c|c|c|c|c|c|c|c|}
\hline \multirow{3}{*}{$\begin{array}{c}\text { TE_3 } \\
\text { Date } \\
* *)\end{array}$} & \multicolumn{4}{|c|}{$\begin{array}{l}\text { Winter period } \\
2005 / 2006\end{array}$} & \multicolumn{3}{|c|}{$\begin{array}{c}\text { Winter period } \\
2006 / 2007\end{array}$} & \multicolumn{3}{|c|}{$\begin{array}{c}\text { Winter period } \\
2011 / 2012\end{array}$} \\
\hline & \multirow{2}{*}{$\begin{array}{l}\text { Day } \\
*) * *)\end{array}$} & TE_3 & $T_{\text {SVHEAT }}$ & $\Delta_{T E}$ & TE_3 & $T_{\text {SVHEAT }}$ & $\Delta_{T E}$ & TE_3 & $T_{\text {SVHEAT }}$ & $\Delta_{T E}$ \\
\hline & & \multicolumn{3}{|c|}{$\left.{ }^{\circ} \mathrm{C} * * *\right)$} & \multicolumn{3}{|c|}{$\left.{ }^{\circ} \mathrm{C} * * *\right)$} & \multicolumn{3}{|c|}{$\left.{ }^{\circ} \mathrm{C} * * *\right)$} \\
\hline 25.12. & $40^{\text {th }}$ & 4.0 & 5.0 & -1.0 & 6.8 & 7.9 & - & 5.5 & 6.7 & -1.2 \\
\hline 30.12. & $45^{\text {th }}$ & 3.8 & 4.8 & -1.0 & 6.0 & 7.0 & - & 5.2 & 6.3 & -1.1 \\
\hline 4.1. & $50^{\text {th }}$ & 3.5 & 4.5 & -1.0 & 5.1 & 6.2 & - & 4.9 & 5.9 & -1.0 \\
\hline 9.1. & $55^{\text {th }}$ & 3.4 & 4.3 & -0.9 & 5.3 & 6.1 & - & 4.7 & 5.6 & -0.9 \\
\hline 14.1. & $60^{\text {th }}$ & 3.0 & 3.9 & -0.9 & 5.7 & 6.3 & - & 4.5 & 5.2 & -0.7 \\
\hline 19.1. & $65^{\text {th }}$ & 2.4 & 3.4 & -1.0 & 5.2 & 6.0 & - & 4.2 & 4.8 & -0.6 \\
\hline 24.1. & $70^{\text {th }}$ & 2.0 & 3.0 & -1.0 & 5.4 & 5.9 & - & 3.9 & 4.4 & -0.5 \\
\hline 29.1. & $75^{\text {th }}$ & 1.4 & 2.3 & -0.9 & 4.5 & 5.1 & - & 3.4 & 3.8 & -0.4 \\
\hline 3.2 . & $80^{\text {th }}$ & 0.9 & 1.5 & -0.6 & 4.0 & 4.7 & - & 2.5 & 2.5 & 0.0 \\
\hline 8.2 . & $85^{\text {th }}$ & 0.6 & 1.0 & -0.4 & 4.0 & 4.5 & - & 1.4 & 0.8 & 0.6 \\
\hline 13.2 . & $90^{\text {th }}$ & 0.6 & 0.7 & -0.1 & 4.3 & 4.5 & - & 0.7 & -0.3 & 1.0 \\
\hline 18.2 . & $95^{\text {th }}$ & 0.6 & 0.7 & -0.1 & 4.6 & 4.7 & - & 0.5 & -0.6 & 1.1 \\
\hline 23.2. & $100^{\text {th }}$ & 0.7 & 0.8 & -0.1 & 4.5 & 4.5 & 0.0 & 0.6 & -0.3 & 0.9 \\
\hline 28.2 . & $105^{\text {th }}$ & 0.8 & 0.8 & 0.0 & 4.4 & 4.4 & 0.0 & 0.9 & 0.2 & 0.7 \\
\hline 5.3. & $110^{\text {th }}$ & 0.9 & 0.5 & 0.4 & 4.6 & 4.4 & 0.2 & 1.1 & 0.6 & 0.5 \\
\hline 10.3 & $115^{\text {th }}$ & 0.9 & 0.3 & 0.6 & 5.3 & 4.7 & 0.6 & 1.2 & 0.5 & 0.7 \\
\hline 15.3 & $120^{\text {th }}$ & 0.9 & 0.2 & 0.7 & 5.8 & 5.0 & 0.8 & 1.5 & 0.6 & 0.9 \\
\hline \multicolumn{2}{|c|}{$\begin{array}{l}\text { Characteristic of } \\
\text { winter period }\end{array}$} & \multicolumn{3}{|c|}{$\begin{array}{l}\text { the highest freezing } \\
\text { index }\left(\boldsymbol{I}_{F}^{\max }, \boldsymbol{I}_{F \text {,surface }}{ }_{\text {max }}\right)\end{array}$} & \multicolumn{3}{|c|}{$\begin{array}{l}\text { the lowest freezing index } \\
\left.\left(\boldsymbol{I}_{F, \text { surface }}\right)\right) \text { and the small- } \\
\text { est freezing depth }\left(\boldsymbol{h}_{\boldsymbol{F}}^{\text {min }}\right)\end{array}$} & \multicolumn{3}{|c|}{$\begin{array}{l}\text { the largest freezing } \\
\text { depth }\left(\boldsymbol{h}_{\boldsymbol{F}}^{\max }\right)\end{array}$} \\
\hline \multicolumn{11}{|c|}{$\begin{array}{l}\text { *) only every } 5 \text { day (data are processed per } 30 \mathrm{~min} \text {.), location of the comparison is at the point } \\
\text { TE_3 } 3 * \text { ) the order of days is adapted to the winter of } 2005 / 06 \text {, identical in } 06 / 07 \text { and } \\
\text { orientation by date in } 2011 / 12 * * *) \text { temperatures }\left({ }^{\circ} \mathrm{C}\right) \text { : } \mathbf{T E} \_3-\text { experimental measurements and } \\
\boldsymbol{T}_{\text {SVHEAT }} \text { - simulations in } \boldsymbol{S V - H E A T}\end{array}$} \\
\hline
\end{tabular}


The main idea of research in the field of monitoring of the temperature regime of the construction of subgrade structure carried out on a railway track model is the determination of its freezing depth, i.e., determining the position of the zero isotherm between the positions of individual thermometers. In this regard, such winter periods are the most important when the highest index of frost was achieved ( $\boldsymbol{I}_{\boldsymbol{F}}$ max, $\boldsymbol{I}_{\boldsymbol{F}}$,surface ${ }^{\max }$ ) and/or the greatest number of freezing days (such days, when the minimum air temperature occurs equal to or less than $-0.1^{\circ} \mathrm{C}$ ), because then it is assumed to achieve the greatest freezing depth in the construction of railway track $\left(\boldsymbol{h}_{F}{ }^{\max }\right)$. This assumption is based on the design methodology described in [3].

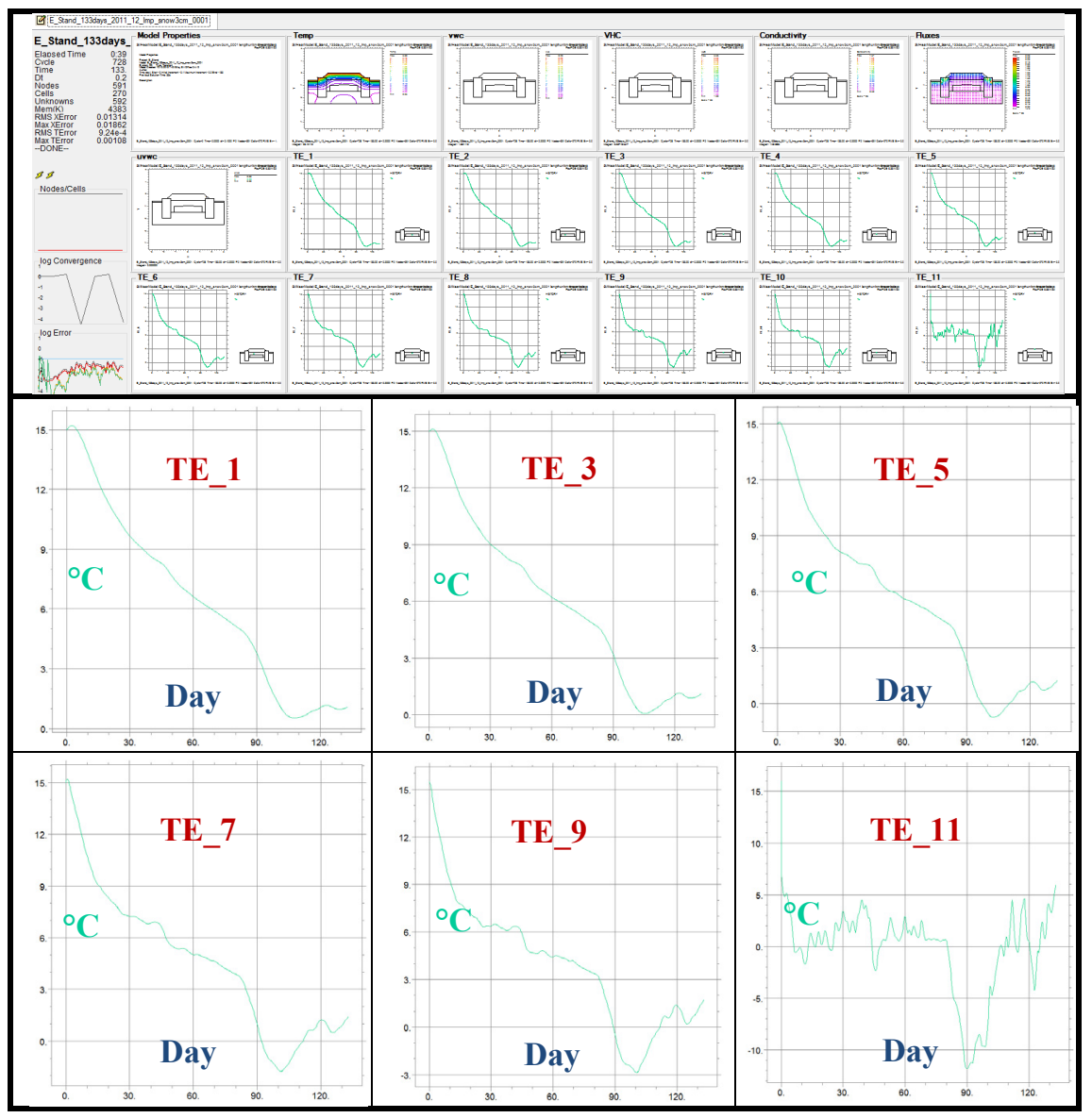

Figure 4: Analysis of the temperature regime in SV-HEAT using FlexPDE at the points TE_1 to TE_11-133 days (5.11.2011-16.3.2012). 
The course of the development of the temperature regime in the winter 2011/12 is shown for illustration in fig. 4, which shows that there has been freezing in the area of subgrade of railway substructure. This fact is characterized by the point TE_3 and all points placed over it achieved negative values of temperatures (there is shown a different temperature range in individual figures, i.e. scale from min. to max. temperature values at the relevant point for winter). This analysis is processed using a model FlexPDE [1], which is part of the software $S V$-HEAT.

The best presentation of the course of temperature (not only from the perspective of mathematical modelling in SV-HEAT, but as well as real temperatures recorded in the Experimental Stand TE_i) are temperatures in the level of subgrade of railway substructure with thermometer localization in the points TE_1 (same height level TE_2) and TE_3 (TE_4), which especially in the cases that it is composed of freezing soil can cause structural failure in the construction of subgrade structure and then failures in geometric position of track. If we follow that there was freezing of the construction of subgrade structure of a mathematical model to subgrade level in each winter periods of 2003-2013, we can conclude that the zero isotherm was situated in close proximity to the point TE_3 in the winter period of 2011/12, but it has reached a level of next point TE_4 (in fig. 1), which is caused by its location closer to the edge of the construction and confirming the real measurement of the Experimental Stand. Winter period 2005/06 is characterized that the zero isotherm "attacked" subgrade, but this was not freezing. Warm winter 2006/07 resulted in that there occurred the lowest temperatures at the TE_3 about $4^{\circ} \mathrm{C}$ in the subgrade, fig. 5.

Analysis and comparison of temperatures in the level of subgrade aforementioned winter periods at the level of point TE_3 is shown in fig. 5, while the point TE_ 5 located above the subgrade illustrates the further course of the transition of temperatures through the structural layers of railway substructure.

A daily animation of temperature regime of individual winter periods is the final phase of mathematical modelling of temperature regime of the construction of railway track, in our case, Experimental Stand DRETM I, while there were selected the hottest and the coldest winter period for the presentation that were recorded during the years 2003-2013 (fig. 6 and fig. 7). Maximum freezing of test model of the construction of railway track for the entire 10 year period of measurements is evident from fig. 7, approx. in $97^{\text {th }}$ day of winter 2011/12.

\section{Conclusion}

In recent decades, it has been discussed more and more talked about global warming, while there are also recorded changes of temperature regime in Slovakia, not only in summer, but also in winter. The mathematical modelling presented and the results of long-term experimental measurements reflect current climatic conditions in the area of Žilina, located in central Europe. Due to the 


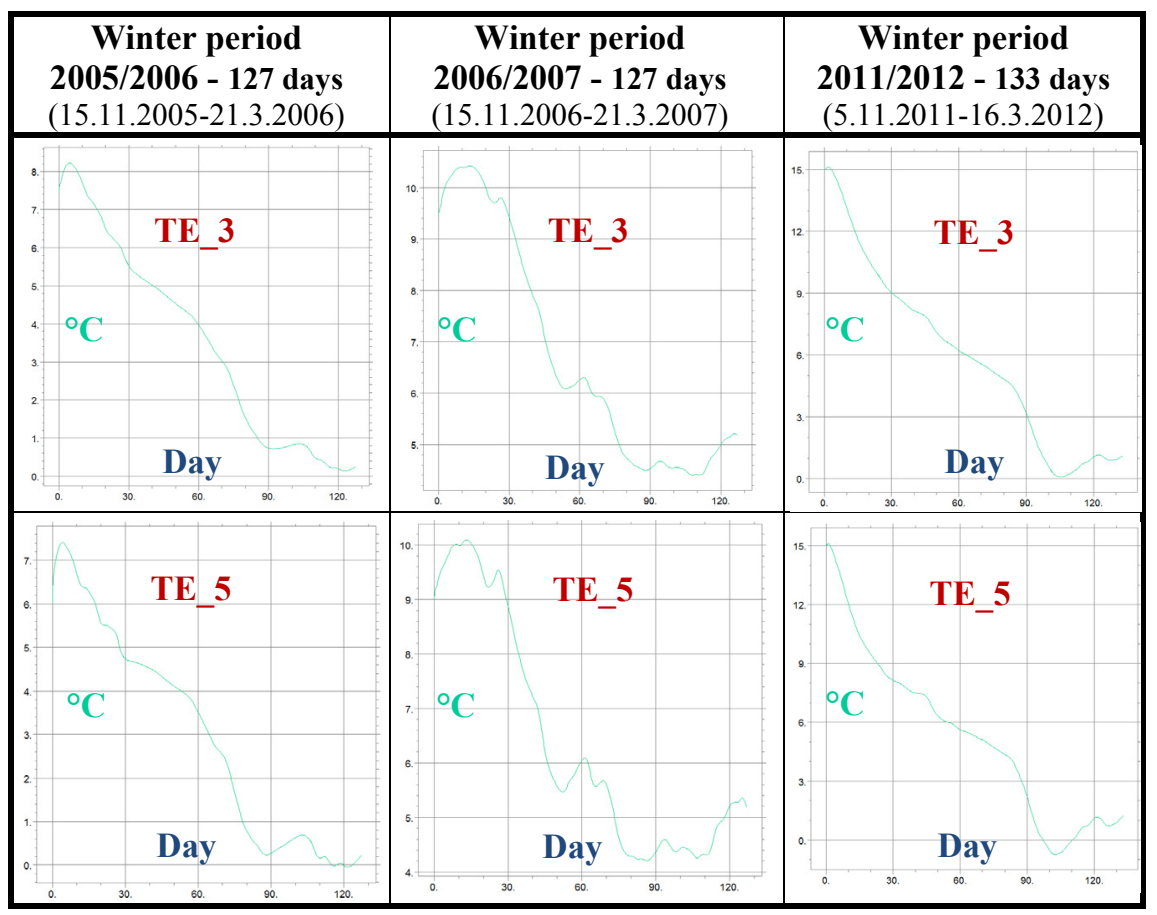

Figure 5: Analysis and comparison of the points TE_3 and TE_5 in winter periods 2005/06, 2006/07 and 2011/12.

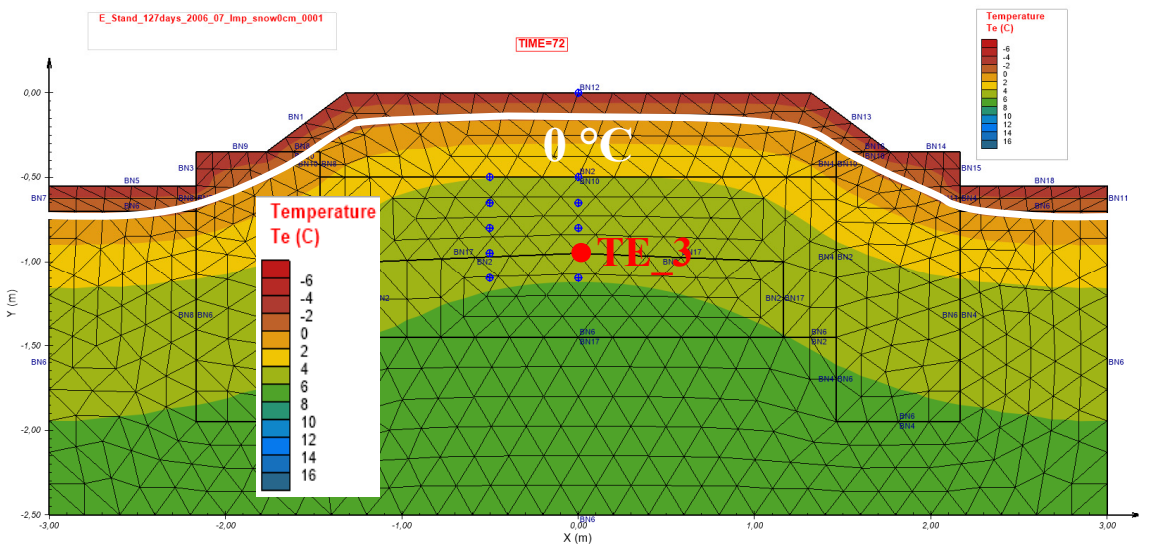

Figure 6: Winter period 2006/07 - the lowest freezing index IF, surface min and the smallest freezing depth of the construction $\boldsymbol{h}_{F}$ min . 


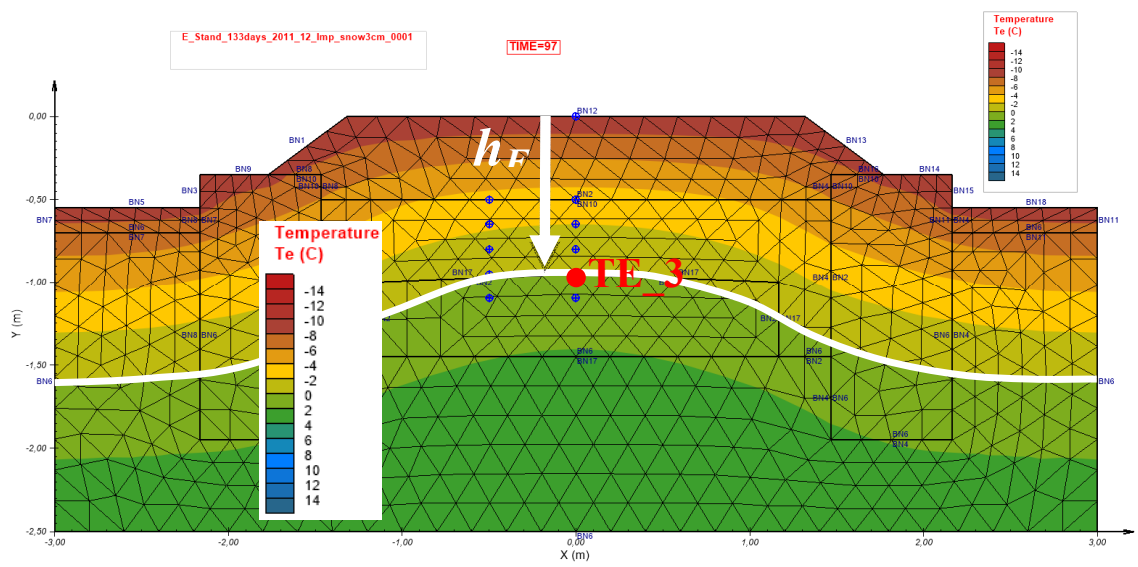

Figure 7: Winter period 2011/12 - the greatest freezing depth of the construction $\boldsymbol{h}_{F}^{\max }$.

fact that there are led some of the trans-European corridors through the Slovak Republic, which are currently being upgraded, the question of design correctness of construction type of subgrade structure and its dimensions in terms of its assessment of the adverse effects of frost is more than actual. Therefore, it is very important to verify the accuracy of currently used methodology of construction design of subgrade structure to the adverse effects of frost and relevance of the inputs used in their own design procedure are necessary and have a major impact not only on the design of the type and dimension of the constructions of subgrade structure, but then on the economy design and then the operating reliability of the construction.

Based on the recent experience with the use of the software product $S V$-HEAT SoilVision performed comparison with real results of experimental monitoring of temperature regime of subgrade structure on the Experimental Stand DRETM I it can be stated that:

1. the mathematical simulation of temperature regime of the construction of railway track using the present software is very useful and gives very good results compared with the values measured on the real construction of railway track model (Experimental Stand DRETM I), and therefore, not necessary, because of the verification of design methodology for sizing the construction of subgrade structure to the adverse effects of frost build real and long-term monitor all other types of constructions of subgrade structure, which is very time- and capital consuming,

2. due to the relevance of the results obtained by mathematical modelling and their possible applications it is:

- very important the first setting of all initial temperatures in each structural layers and subgrade of railway track model, 
- necessary that the mathematical model corresponds exactly to the shape (embankment, sidehill, cut) and dimension of reality (location and height of all monitored locations of the construction of subgrade structure),

- needed to know and use only the relevant values of coefficients of thermal conductivity $\lambda$ of building materials built in the construction of railway track changing during the year and are mainly influenced by their granulometric composition, density and humidity,

- knowledge of the occurrence and the total time of the snow cover in different weeks, or months of the winter period, as it has a significant thermal insulation character, and therefore, impact on the depth of penetration of the zero isotherm into the construction of the railway track.

Based on previously conducted experimental measurements and mathematical modelling of the temperature regime of the construction of subgrade structure and requirement of exact approach to the dimensioning of construction of subgrade structure to the adverse effects of frost, there was built another model of railway track (Experimental Stands DRETM II Type 1 and Type 2) in fig. 8, which represents the railway track extending in the embankment and representing two types of the construction of subgrade structure (with and without a protective layer of subgrade) for the expansion of the real knowledge of the climatic factors on the temperature regime of subgrade structure and acquisition of relevant inputs for mathematical modelling of temperature regime of subgrade structure of railway track.

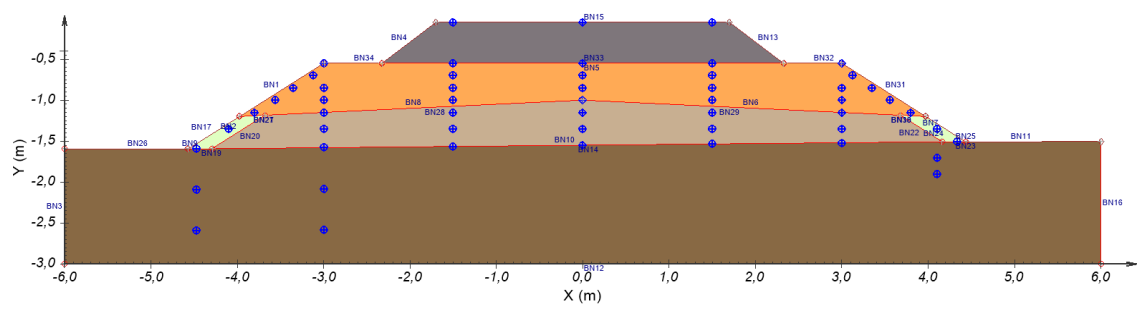

Figure 8: Newly built model DRETM II Type 2 of railway track.

In order to objectively monitor and determine the course of the temperature regime of subgrade structure, there are built in - in each construction of railway track model - in its cross-section profile - a total of 50 thermometers and in order to capture the humidity conditions in the construction and their changes during the winter period, it is possible to continuously monitor the actual humidity of materials incorporated in five probes located in each profile, which has, in addition to the presence of snow cover on the surface of the construction, a principal impact on the permeation of zero isotherm to its subgrade. It is clear that experimental measurements will be simultaneously realized on the Experimental Stand DRETM I, where will be possible to provide mutual comparison of temperature regime of shape, construction and materially different constructions of railway track model. 


\section{Acknowledgement}

The contribution is a partial output of solution grant project VEGA 1/0756/12 "Experimental monitoring and mathematical modelling of thermal regime of railway subgrade structure" (2012-2015) [5].

\section{References}

[1] SV-HEAT - 2D/3D Geothermal modelling, FlexPDE, SVOFFICE 2009 Geotechnical Modelling Suite, SoilVision systems Ltd., Saskatoon, Saskatchenwan, Canada, 2014, http://www.soilvision.com

[2] Ižvolt, L., Dobeš, P. \& Pitoňák, M., Some experience and preliminary conclusions from the experimental monitoring of the temperature regime of railway subgrade. Proc. of COMPRAIL 2014, http://www.wessex.ac.uk

[3] TNŽ 736312 Design of construction layers of railway subgrade. Standard of Slovak Railways. GR ŽSR, 2005, http://www.zsr.sk

[4] Ižvolt, L., Dobeš, P. \& Mečár, M., Contribution to the methodology of the determination of the thermal conductivity coefficients $\lambda$ of materials applied in the railway submase structure. Communications - Scientific Letters of the University of Žilina, 2(15), 2013, pp. 9-17, http://www.uniza.sk/komunikacie

[5] VEGA 1/0756/12 Experimental monitoring and mathematical modelling of thermal regime of railway subgrade structure. Scientific research, Dep. of Railway Engineering, Fac. of Civil Engineering, University of Žilina, Žilina, http://svf.uniza.sk/kzsth. VEGA - Ministry of Education, Science \& Research of the Slovak Republic, Bratislava, SK, 2012-2015, http://www.minedu.sk 